\title{
GPCR Signaling and mTORC1 Regulation
}

Chase H. Melick ${ }^{1,2,3 \dagger}$, Tshering D. Lama-Sherpa ${ }^{1,2,3 \dagger}$, Adna Curukovic ${ }^{1,2,3}$, Jenna L. Jewell $^{1,2,3, \text { * }}$

${ }^{1}$ Department of Molecular Biology, University of Texas Southwestern Medical Center, Dallas, TX 75390, USA

${ }^{2}$ Harold C. Simmons Comprehensive Cancer Center, University of Texas Southwestern Medical Center, Dallas, TX 75390, USA

${ }^{3}$ Hamon Center for Regenerative Science and Medicine, University of Texas Southwestern Medical Center, Dallas, TX 75390, USA

† These authors contributed equally to this work

* Correspondence: Jenna.Jewell@UTSouthwestern.edu 
Running title:

Regulation of mTORC1 Signaling

Correspondence:

Jenna L. Jewell, Ph.D., University of Texas Southwestern Medical Center

Address: NA5.508, 6000 Harry Hines Blvd, Dallas, TX 75390, USA

Office phone: 214-648-1086

Fax: 214-648-1488

E-mail: Jenna.Jewell@UTSouthwestern.edu

Numbers:

Number of text pages: 13

Number of tables: 2

Number of figures: 3

Number of references: 143

Number of words in abstract: 84

Number of words in introduction: 222

Number of words in discussion: 140 
Abbreviations:

4EBP1 elF4E-binding protein 1

AKAP A-kinase anchoring protein

AKT PI3K- Rac-alpha Ser/Thr-protein kinase

AMPK 5'AMP-activated protein kinase

Arf1 Adenosine diphosphate ribosylation factor 1

ArfGAP1 ADP-ribosylation factor GTPase-activating protein 1

cAMP 3',5'-cyclic adenosine monophosphate

CASTOR1 Cellular arginine sensor for mTORC1

CDK1 Cyclin-dependent kinase 1

DEPTOR DEP-domain-containing mTOR-interacting protein

DAG Diacylglycerol

elF4B Eukaryotic translation initiation factor 4B

ERK Extracellular signal-regulated kinase

FKBP12 Prolyl-isomerase FK506-binding protein 12

GAP GTPase activating protein

GATOR1 GAP activity towards the Rags 1

GDP Guanosine diphosphate

GEF Guanine nucleotide exchange factor

GPCRs G-protein coupled receptors

GPR137B G-protein coupled receptor protein 137B

GTP Guanosine triphosphate

HEK293T Human embryonic kidney 293T 


\begin{tabular}{ll} 
IKK $\beta$ & IKB kinase $\beta$ \\
IP3 & Inositol 1,4,5-triphosphate \\
KICSTOR & KPTN, ITFG2, C12orf66, and SZT2 \\
mLST8 & Mammalian lethal with Sec13 protein 8 \\
MSN & Medium spiny neuron \\
mTOR & Mammalian target of rapamycin \\
mTORC1 & mTOR complex 1 \\
PDE & Phosphodiesterase \\
PKA & Protein kinase A \\
PRAS40 & Proline-rich Akt substrate 40 kDa \\
Raptor & Regulatory protein associated with mTOR \\
REDD1 & DNA damage and development 1 \\
Rheb & Ras homolog enriched in brain \\
S6K1 & p70 ribosomal S6 kinase 1 \\
SLC38A9 & Solute carrier family 38 member 9 \\
SREBP & Sterol-responsive element-binding protein \\
TFEB & Transcription factor EB \\
TOR & Target of rapamycin \\
TSC & Tuberous sclerosis complex \\
TSHR & Thyroid stimulating hormone receptor \\
ULK1 & Unc-51 like autophagy activating kinase 1 \\
\hline Th & \\
\hline
\end{tabular}




\section{Abstract}

The mammalian target of rapamycin (mTOR) senses upstream stimuli to regulate numerous cellular functions such as metabolism, growth, and autophagy. Increased activation of mTOR complex 1 (mTORC1) is typically observed in human disease and continues to be an important therapeutic target. Understanding the upstream regulators of mTORC1 will provide a crucial link in targeting hyperactivated mTORC1 in human disease. In this mini-review, we will discuss the regulation of mTORC1 by upstream stimuli, with a specific focus on G-protein coupled receptor (GPCR) signaling to mTORC1.

\section{Significance statement}

mTORC1 is a master regulator of many cellular processes and is often hyperactivated in human disease. Therefore, understanding the molecular underpinnings of GPCR signaling to $\mathrm{mTORC} 1$ will undoubtedly be beneficial for human disease.

\section{Introduction}

Over the span of 20 years since the mammalian target of rapamycin (mTOR) was discovered, numerous findings have highlighted the importance of mTOR as the central node in a network of signaling pathways that control cell growth, metabolism, and autophagy (Brown et al., 1994; Sabatini et al., 1994; Sabers et al., 1995). mTOR was discovered following the identification of its inhibitor, rapamycin, which was thought to be an antifungal and immunosuppressant agent. Genetic screens in yeast by several groups found that the prolyl-isomerase FK506-binding protein 12 (FK506) and 
rapamycin form a complex and inhibit mTOR (Heitman et al., 1991; Stan et al., 1994; Zheng et al., 1995). Aberrant mTOR activation has been implicated in several human pathologies. mTOR dysregulation can result in the overgrowth of cancers, and pathologies associated with aging and metabolic disease. Rapamycin and analogs of rapamycin (rapalogs) are currently used to treat mTORC1 hyperactivated diseases in the clinic (Tian et al., 2019). The complete mechanistic insight of mTORC1 signaling is still being elucidated and a new generation of drugs are being investigated to better target mTOR (Popova and Jücker, 2021). mTORC1 activation occurs in response to different extracellular and intracellular stimuli. This mini-review will provide a brief overview of mTORC1 and discuss the regulation of mTORC1 by upstream stimuli. We will specifically focus on G protein-coupled receptors (GPCRs) with respect to mTORC1 regulation, and the recent advances in the field.

\section{mTORC1}

The evolutionarily conserved Ser/Thr protein kinase mTOR belongs to the phosphatidylinositide 3 kinase-related kinase family (Hay and Sonenberg, 2004). mTOR is the catalytic component of two distinct protein complexes referred to as mTORC1 and mTORC2. This mini-review will not discuss mTORC2, refer to (Liu and Sabatini, 2020). There are three main core components of mTORC1: mTOR, Raptor, and mLST8 (Hara et al., 2002; Kim et al., 2002; Kim et al., 2003). The Raptor subunit of mTORC1 facilitates mTOR substrate recognition and phosphorylation (Nojima et al., 2003; Schalm et al., 2003). mTORC1 activity is positively regulated by mammalian lethal with SEC13 protein 8 (mLST8). Additional research in the future may identify new mTORC1 
components. mTORC1 controls cellular events like translation, growth factor signaling, autophagy, lysosome biogenesis, and lipid synthesis (Melick and Jewell, 2020; Saxton and Sabatini, 2017). Protein translation is regulated by mTORC1 mainly through phosphorylation of mTORC1 substrates like p70 ribosomal S6 kinase 1 (S6K1) and elF4E-binding protein 1 (4EBP1). Similarly, growth factor signaling and autophagy are regulated by $\mathrm{mTORC} 1$ through the phosphorylation of $\mathrm{mTORC} 1$ substrates growth factor receptor-bound protein 10 (Grb10) and Unc-51 like autophagy activating kinase 1 (ULK1), respectively. Lysosomes are important for cellular recycling and function as the central hub for mTORC1 signaling. mTORC1 also supports lysosomal biogenesis through phosphorylation of transcription factor EB (TFEB). Furthermore, mTORC1 regulates lipid synthesis through Lipin1 and S6K1 phosphorylation, and positively regulates sterol-responsive element-binding protein (SREBP). Among the different substrates of mTORC1, the phosphorylation sites on S6K1 (Thr 389), 4EBP1 (Ser 65, Thr 37, and Thr46), and ULK1 (Ser 758) are commonly accepted as markers of mTORC1 activity. Other reviews have discussed mTORC1 substrates and downstream signaling in more detail (Liu and Sabatini, 2020; Saxton and Sabatini, 2017).

\section{Upstream stimuli that regulate mTORC1 activity}

\section{Growth factor signaling}

mTORC1 is regulated by several growth factors (Figure 1). Growth factor signaling converges on tuberous sclerosis complex (TSC), which inhibits small G-protein Ras homolog enriched in brain (Rheb) (Inoki et al., 2003a; Tee et al., 2003). TSC is a 
GTPase-activating protein (GAP) and interacts with Rheb to hydrolyze Rheb-GTP (active state) to Rheb-GDP (inactive state). Rheb binds to and allosterically activates mTORC1 kinase activity via a conformational change (Long et al., 2005; Yang et al., 2017). Growth factors signaling through AKT (Potter et al., 2002), ERK (Ma et al., 2005), p90 ribosomal S6 kinase 1 (Roux et al., 2004), IKKß (Lee et al., 2007), or MAPKactivated protein kinase 2 ( $\mathrm{Li}$ et al., 2003) phosphorylate and inhibit TSC2 resulting in mTORC1 activation. Low energy status, hypoxia, and DNA damage enhance the TSC GAP to inhibit mTORC1 (Liu and Sabatini, 2020). Hypoxia leads to TSC2 activation through REDD1 (Brugarolas et al., 2004; DeYoung et al., 2008). Similarly, nutrient deprivation can trigger AMPK to phosphorylate and activate the GAP activity of TSC (Corradetti et al., 2004; Inoki et al., 2003b). DNA damage induces phosphorylation of tumor suppressor protein 53 and leads to an AMPK-dependent TSC activation resulting in mTORC1 inhibition (Feng et al., 2007).

\section{Amino acid signaling}

Amino acids promote mTORC1 lysosomal localization and its subsequent activation (Rogala et al., 2019; Sancak et al., 2010; Sancak et al., 2008). Amino acid regulation of mTORC1 does not rely on TSC signaling. Multiple groups have shown that amino acid and growth factors are two distinct pathways in terms of mTORC1 activation (Demetriades et al., 2014; Hara et al., 1998; Menon et al., 2014; Sancak et al., 2008; Smith et al., 2005a). In TSC knockout cells, amino acid starvation still inhibits mTORC1 (Smith et al., 2005a). The discovery of Rag GTPases coupled to mTORC1 at the lysosome has shed some important insight into amino acid signaling to mTORC1 (Kim 
et al., 2008; Sancak et al., 2008). The Rag GTPase family consists of RagA, RagB, RagC, and RagD (Sekiguchi et al., 2001). Four possible distinct complexes can occur, where RagA or RagB can heterodimerize with either RagC or RagD. Amino acid promotes RagA/B loading with GTP, RagC/D loading with GDP, and Rag-mTORC1 binding on the lysosomal surface. Rheb GTPase associates and directly activates mTORC1 (Long et al., 2005). The Ragulator anchors the Rag GTPase-mTORC1 complex to the surface of the lysosome leading to mTORC1 activation (Sancak et al., 2010). Recently, a Rag GTPase-independent pathway was identified, where Asn and Gln signal to mTORC1. In this Rag GTPase-independent pathway, it was found that the v-ATPase, lysosomal function, and a small GTPase called ADP-ribosylation factor 1 (Arf1) are required for the activation of mTORC1 (Jewell et al., 2015). Additional components involved in this pathway are yet to be discovered. Our recent study found that mTORC1 is activated by 10 out of 20 standard amino acids, at different concentrations and time frames (Meng et al., 2020). Met, His, Arg, Ala, Leu, Thr, Val, and Ser activated mTORC1 through the Rag-dependent pathway (Figure 2A) while Asn and Gln work through a Rag-independent pathway (Figure 2B). CASTOR1, SLC38A9, Sestrin2, and SAMTOR are the identified sensors for Rag-dependent pathway (Liu and Sabatini, 2020). Sensors for amino acids such as Ala, His, Ser, Thr, and Val have not yet been identified. Further details on amino acid sensors can be found in other reviews (Kim and Guan, 2019; Liu and Sabatini, 2020). The subcellular location or interacting proteins of mTORC1 under amino acid-deficient conditions are not completely understood. We recently identified the ADP-ribosylation factor GTPase-activating protein 1 (ArfGAP1) as a crucial regulator of mTORC1 (Meng et al., 2021). ArfGAP1 
interacts with mTORC1 in the absence of amino acids and inhibits mTORC1 lysosomal localization and activation. Interestingly, ArfGAP1 represses mTORC1 lysosomal recruitment and cell growth independently of its GTPase-activating function. Since lysosomal localization is critical for mTORC1 activation, future studies on understanding where mTORC1 is localized when amino acids are not present will be crucial. Also, understanding what factors regulate the trafficking of $\mathrm{mTORC} 1$ to the lysosome will be beneficial.

\section{GPCR-G $\alpha_{s}$ signaling}

GPCRs are seven transmembrane domain receptors that make up the largest family of membrane proteins. Classically, after a relevant ligand or agonist binds to a GPCR, the activation of downstream GPCR signaling cascades is initiated (Hilger et al., 2018). GPCRs are coupled with G-proteins $\alpha, \beta$, and $\gamma$. GDP-bound $\mathrm{G} \alpha$ and G $\beta \gamma$ are attached to the plasma membrane in the absence of a ligand ( $\mathrm{Li}$ et al., 2002). However, when a ligand/agonist binds to the GPCR, it is activated and acts as a guanine nucleotide

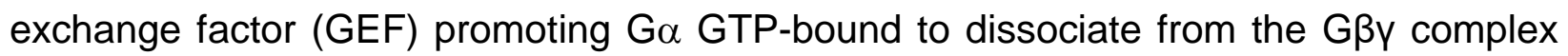
(Figure 3). The intrinsic GTPase activity of $\mathrm{G} \alpha$ hydrolyzes GTP after which $\mathrm{G} \alpha$ reassociates with the GßY dimer until the next round of activation (Hanlon and Andrew, 2015; Vogler et al., 2008). GßY dimer recruits GPCR kinases as a negative feedback loop to phosphorylate and subsequently inhibit it. The phosphorylation leads to the GPCR receptor internalization following $\beta$-arrestin binding. Traditionally, GPCR signaling was thought to take place at the cell surface, which then leads to receptor endocytosis (Mohan et al., 2012), but intracellular GPCR signaling also exists (Eichel 
and von Zastrow, 2018). Ga consists of four different protein families: $\mathrm{G} \alpha_{\mathrm{s}}, \mathrm{G} \alpha_{\mathrm{i} / \mathrm{o}}, \mathrm{G} \alpha_{\mathrm{q} / 11}$, and $\mathrm{G}_{\alpha_{12 / 13}}$ (Wettschureck and Offermanns, 2005). Among them, $\mathrm{G} \alpha_{\mathrm{s}}$ and $\mathrm{G} \alpha_{\mathrm{i} / \mathrm{o}}$ regulate adenylate cyclase $(A C)$, where $G \alpha_{s}$ activates $A C$ and $G \alpha_{i / o}$ inhibits $A C$. The GTP-bound $\mathrm{G} \alpha_{\mathrm{s}}$ binds to and activates AC which catalyzes the conversion of ATP to cAMP ultimately increasing the intracellular cAMP levels (Sassone-Corsi, 2012). In mammals, there are 9 different isoforms of $A C(A C 1-9)$ and a soluble $A C . A C 1$ and $A C 8$ are tissuespecific to neuronal cells while AC5 is tissue-specific to heart and striatum (Defer et al., 2000). $\mathrm{G} \alpha_{s}$ proteins stimulate AC by interacting with the cytoplasmic catalytic domains, C1 and C2 (Wittpoth et al., 1999). cAMP acts as a secondary messenger and serves to regulate multiple physiological processes. One of the major targets of cAMP is protein kinase A (PKA) (Beebe, 1994). Other targets include guanine exchange proteins activated by cAMP, cyclic nucleotide-gated channels, and popeye domain-containing proteins (Zaccolo and Pozzan, 2003; Zaccolo et al., 2021). $\mathrm{G} \alpha_{\mathrm{q} / 11}$ binds and activates phospholipase C to convert phosphatidylinositol 4,5-bisphosphate to IP3 and DAG (Kadamur and Ross, 2013). Ga $\alpha_{12 / 13}$ targets Rho GEFs to regulate actin cytoskeleton (Suzuki et al., 2009) such as neurite retraction (Katoh et al., 1998). More details on GPCR signaling are described in other reviews (Hanlon and Andrew, 2015; Pavlos and Friedman, 2017).

\section{GPCR signaling and $\mathrm{mTORC} 1$ regulation}

PKA is a holoenzyme that contains two catalytic and two regulatory subunits (Wong and Scott, 2004). The regulatory subunits of PKA are Rla, RI $\beta, R I l \alpha$, and RII $\beta$. The regulatory subunit $\mathrm{RI}$ localizes in the cytoplasm and $\mathrm{RII}$ is found at the membranes of 
organelles (Doskeland et al., 1993; llouz et al., 2012). Increased cAMP levels activate PKA by binding to the regulatory subunits and result in the release of the catalytic subunit (Kapiloff et al., 2014; Taylor et al., 2021). The catalytic subunit of PKA phosphorylates several downstream targets including cAMP-response-element-binding protein (CREB) (Beebe, 1994). Previously, Rla has also been shown to interact with and activate mTOR through an unknown mechanism (Mavrakis et al., 2006; 2007). A recent study from our lab uncovered a link between GPCR-G $\alpha_{s}$ signaling in the regulation of mTORC1 activity through PKA activation (Jewell et al., 2019). Gos-coupled GPCRs such as adrenergic, glucagon, and vasopressin receptors through their respective ligand leads to increased cAMP-PKA signaling resulting in Raptor Ser 791 phosphorylation and mTORC1 inhibition. cAMP-PKA mediated mTORC1 inhibition was seen in breast, prostate, and pancreatic cancer, non-small cell lung carcinoma, nearhaploid human cell line (HAP1), osteosarcoma epithelial cell, human embryonic kidney, and mouse embryonic fibroblast cells (Jewell et al., 2019; Xie et al., 2011). This phenomenon was consistently seen in vivo where mice injected with epinephrine had decreased mTORC1 activity in the liver and brain (Jewell et al., 2019). Additionally, the pharmacological induction of cAMP levels in mouse embryonic fibroblasts and HEK293 cells have also been reported to inhibit mTORC1 (Xie et al., 2011). Furthermore, studies in 3T3-L1 adipocytes (Mullins et al., 2014; Scott and Lawrence, 1998; Soliman et al., 2010), rat hepatocytes (Mothe-Satney et al., 2004), thyroid carcinoma cells (Rocha et al., 2008), lymphoblasts (Monfar et al., 1995), perfused rat liver (Baum et al., 2009), and smooth muscle cells (Scott et al., 1996) reported that high cAMP levels inhibits mTORC1. There are additional examples of regulation of GPCR signaling and mTORC1 
activity from other groups (Table 1). GPCRs can potentially be great therapeutic targets due to their broad expression throughout different tissue and cell types (Bohme and Beck-Sickinger, 2009; Insel et al., 2012). Most research have focused on the upstream stimuli that activate mTORC1. However, not much is known about the signaling pathways that negatively regulate mTORC1. Therefore, it is critical to delineate the mechanistic detail of how GPCRs coupled to $\mathrm{G} \alpha_{s}$ proteins regulate mTORC1.

Several studies have reported that GPCRs couple to $\mathrm{G} \alpha_{\mathrm{s}}$ increase cAMP and inhibit mTORC1, but there are also reports of GPCR-G $\alpha_{s}$ signaling enhancing mTORC1 activity (Arvisais et al., 2006; Wang et al., 2014). BRAF mutated thyroid carcinoma cell lines following GPCR stimulation showed an increase in mTORC1 activity, but the wild type cells showed a decrease in mTORC1 activity (Rocha et al., 2008). Similarly, another study has revealed that PKA directly phosphorylates mTOR and Raptor activating mTORC1 in 3T3-L1 adipocytes (Liu et al., 2016). mTORC1 activation in response to GPCR signaling might be the result of the differences in cell types and their response to altered cAMP signaling. Additionally, GPCR signaling to mTORC1 may have different biological outcomes in different tissues and cell types. There is also evidence of direct interaction between a GPCR and mTORC1 machinery. Lysosome localized GPCR-like protein GPR137B was shown to positively regulate mTORC1 lysosomal translocation and RagA-GTP loading (Gan et al., 2019). Future work on the crosstalk between GPCR signaling and $\mathrm{mTORC} 1$ may clarify how cAMP levels regulate mTORC1. 


\section{A-kinase anchoring proteins and $\mathrm{mTORC1}$ regulation}

AKAPs are scaffolding proteins that bind PKA through regulatory subunit domains (Carnegie et al., 2009). AKAPs anchor PKA holoenzymes to distinct subcellular locations maintaining distinct cAMP signaling pathways (Kritzer et al., 2012). Disruption of AKAPs have also been linked to several diseases. For example, AKAP1, AKAP12, and AKAP13 have been reported to play a role in cancer (Bucko and Scott, 2021). Since AKAPs are tissue-specific and compartmentalized, they have the potential to become useful therapeutic targets in addition to biomarkers for specific human diseases (Esseltine and Scott, 2013; Wong and Scott, 2004). We recently showed that AKAP8L interacts with mTORC1 in the cytoplasm. AKAP8L loss leads to reduced mTORC1mediated phenotypes such as cell growth, cellular proliferation, and translation (Melick et al., 2020). However, AKAP8L did not inhibit mTORC1 through PKA. We found that AKAP13 (also known as AKAP-Lbc) is an important mTORC1 binding partner and inhibits mTORC1 through PKA. AKAP13 scaffolds PKA next to mTORC1 leading to Raptor Ser791 phosphorylation and mTORC1 inhibition. Additionally, AKAP13 plays a role in the mTORC1-mediated processes of cell proliferation, cell size, and lung tumorigenesis (Zhang et al., 2021). Previous studies found that AKAP13 promotes ERK signaling (Smith et al., 2010), and displays GEF activity for RhoA promoting activation of p38 $\alpha$ (Pérez López et al., 2013). ERK signaling is known to activate mTORC1 by inhibiting TSC (Ma et al., 2005) and p38 $\alpha$ has been previously reported to negatively alter TSC function by promoting TSC and 14-3-3 binding (Li et al., 2003; Shumway et al., 2003). However, the pharmacological inhibition of ERK signaling did not change Raptor Ser 791 phosphorylation and p38 $\alpha$ depletion did not alter mTORC1 activity 
(Zhang et al., 2021). Similarly, it was found that TSC knockout cells also did not affect Raptor Ser791 phosphorylation (Jewell et al., 2019) indicating that AKAP13-mediated regulation of mTORC1 may be independent of ERK and p38 $\alpha$ signaling. Moreover, it has been shown that a mitochondrial-associated AKAP, AKAP1, promotes mTORC1 activation through the interaction and suppression of Sestrin2 (Rinaldi et al., 2017). Additional research on AKAPs will be important to characterize the PKA signaling to mTORC1.

\section{Phosphodiesterase and mTORC1 regulation}

PDEs degrade cAMP to negatively regulate $\mathrm{G} \alpha_{\mathrm{s}}$ signaling (Sassone-Corsi, 2012). Among 11 characterized PDE family members, PDE4, PDE6, and PDE8 are the main phosphodiesterases that hydrolyze CAMP (Bolger, 2021). In recent years, several pharmacological inhibitors for cAMP substrate specific PDEs have been identified (Table 2). A direct role of PDEs in cAMP-mediated mTORC1 regulation is not known yet. However, some studies indicate that PDEs might play a role in mTORC1 regulation. PDE4 isoform B inhibition increased cAMP signaling and inhibited growth in diffuse large B-cell lymphoma (Smith et al., 2005b). Since, mTORC1 is associated with growth, PDE4B may be involved in mTORC1 regulation. Similarly, PDE3, which hydrolyzes both cAMP and CGMP, has been found to regulate mTORC1 activation and $\beta$-cell proliferation. cGMP can also promote mTORC1 activation through PKG-mediated Raptor phosphorylation at Ser 791 (Liu et al., 2018). Further research on the role of PDE mediated cAMP and cGMP hydrolyzation and $\mathrm{mTORC1}$ regulation will be important. Rapamycin and rapalogs are the only compounds that have been shown to 
have clinical efficacy in targeting mTORC1. However, studies show that prolonged treatment with these inhibitors may have an off-target effect on mTORC2 and exacerbate insulin resistance in mice (Fraenkel et al., 2008; Lamming et al., 2012). Therefore, PDE inhibitors might provide an alternative to negatively regulate mTORC1 by increasing cAMP signaling. Currently, there are multiple FDA-approved drugs that inhibit PDEs that includes sildenafil, vardenafil, tadalafil, avanafil, apremilast, crisaborole, and roflumilast. Since PDE inhibitors are already in use in the clinic, combining PDE inhibitors with GPCR targeting drugs (agonists) could provide therapeutic benefits in targeting mTORC1 hyperactivated diseases.

\section{Conclusions}

mTORC1 dysregulation can result in several human diseases such as cancer, metabolic disorders, and neurodegeneration. Exploring amino acid sensors upstream of mTORC1 and delineating specific amino acid pathways could result in novel clinical treatment options. Furthermore, since GPCRs are the most common FDA-approved drug target on the market today (Sriram and Insel, 2018), we believe that understanding how mTORC1 is regulated by GPCRs could have an immediate impact on mTORC1mediated human diseases. $\mathrm{G} \alpha_{\mathrm{s}}$-coupled GPCRs agonists in combination with clinically available PDE inhibitors could present novel ways to target mTORC1. Although, a more comprehensive understanding of the relationship between GPCR signaling and how it regulates mTORC1 will need to be investigated in the future. Determining or identifying other components involved in this pathway that regulate mTORC1 like phosphodiesterase could also provide more potential therapeutic targets. 


\section{Acknowledgments}

We thank the Jewell lab. Figures were created using BioRender.com.

\section{Authorship Contributions}

Wrote or contributed to the writing of the manuscript: Chase H. Melick, Tshering D. Lama-Sherpa, Adna Curukovic, Jenna L. Jewell. 


\section{References}

Arvisais, E.W., Romanelli, A., Hou, X., and Davis, J.S. (2006). AKT-independent phosphorylation of TSC2 and activation of mTOR and ribosomal protein S6 kinase signaling by prostaglandin F2alpha. $\mathrm{J}$ Biol Chem 281, 26904-26913. 10.1074/jbc.M605371200.

Banskota, S., Gautam, J., Regmi, S.C., Gurung, P., Park, M.H., Kim, S.J., Nam, T.G., Jeong, B.S., and Kim, J.A. (2016). BJ-1108, a 6-Amino-2,4,5-Trimethylpyridin-3-ol Analog, Inhibits Serotonin-Induced Angiogenesis and Tumor Growth through PI3K/NOX Pathway. PLoS One 11, e0148133. 10.1371/journal.pone.0148133.

Barnes, P.J. (2013). Theophylline. Am J Respir Crit Care Med 188, 901-906. 10.1164/rccm.201302-0388PP.

Barroso-Chinea, P., Luis-Ravelo, D., Fumagallo-Reading, F., Castro-Hernandez, J., Salas-Hernandez, J., Rodriguez-Nuñez, J., Febles-Casquero, A., Cruz-Muros, I., Afonso-Oramas, D., Abreu-Gonzalez, P., et al. (2020). DRD3 (dopamine receptor D3) but not DRD2 activates autophagy through MTORC1 inhibition preserving protein synthesis. Autophagy 16, 1279-1295. 10.1080/15548627.2019.1668606.

Baum, J.I., Kimball, S.R., and Jefferson, L.S. (2009). Glucagon acts in a dominant manner to repress insulin-induced mammalian target of rapamycin complex 1 signaling in perfused rat liver. American Journal of Physiology-Endocrinology and Metabolism 297, E410-E415. 10.1152/ajpendo.00042.2009.

Baye, J. (2012). Roflumilast (daliresp): a novel phosphodiesterase-4 inhibitor for the treatment of severe chronic obstructive pulmonary disease. P T 37, 149-161.

Beebe, S.J. (1994). The CAMP-dependent protein kinases and CAMP signal transduction. Semin Cancer Biol 5, 285-294.

Bohme, I., and Beck-Sickinger, A.G. (2009). Illuminating the life of GPCRs. Cell Commun Signal 7, 16. 10.1186/1478-811X-7-16.

Bolger, G.B. (2021). The PDE-Opathies: Diverse Phenotypes Produced by a Functionally Related Multigene Family. Trends in Genetics 37, 669-681. https://doi.org/10.1016/j.tig.2021.03.002. 
Brown, E.J., Albers, M.W., Shin, T.B., Ichikawa, K., Keith, C.T., Lane, W.S., and Schreiber, S.L. (1994). A mammalian protein targeted by G1-arresting rapamycinreceptor complex. Nature 369, 756-758. 10.1038/369756a0.

Brugarolas, J., Lei, K., Hurley, R.L., Manning, B.D., Reiling, J.H., Hafen, E., Witters, L.A., Ellisen, L.W., and Kaelin, W.G., Jr. (2004). Regulation of mTOR function in response to hypoxia by REDD1 and the TSC1/TSC2 tumor suppressor complex. Genes Dev 18, 2893-2904. 10.1101/gad.1256804.

Bucko, P.J., and Scott, J.D. (2021). Drugs That Regulate Local Cell Signaling: AKAP Targeting as a Therapeutic Option. Annu Rev Pharmacol Toxicol 61, 361-379. 10.1146/annurev-pharmtox-022420-112134.

Carlessi, R., Chen, Y., Rowlands, J., Cruzat, V.F., Keane, K.N., Egan, L., Mamotte, C., Stokes, R., Gunton, J.E., Bittencourt, P.I.H., and Newsholme, P. (2017). GLP-1 receptor signalling promotes beta-cell glucose metabolism via mTOR-dependent HIF-1alpha activation. Sci Rep 7, 2661. 10.1038/s41598-017-02838-2.

Carnegie, G.K., Means, C.K., and Scott, J.D. (2009). A-kinase anchoring proteins: from protein complexes to physiology and disease. IUBMB Life 61, 394-406. 10.1002/iub.168.

Chang, H.H., Young, S.H., Sinnett-Smith, J., Chou, C.E., Moro, A., Hertzer, K.M., Hines, O.J., Rozengurt, E., and Eibl, G. (2015). Prostaglandin E2 activates the mTORC1 pathway through an EP4/CAMP/PKA- and EP1/Ca2+-mediated mechanism in the human pancreatic carcinoma cell line PANC-1. Am J Physiol Cell Physiol 309, C639649. 10.1152/ajpcell.00417.2014.

Choi, M.S., Moon, S.M., Lee, S.A., Park, B.R., Kim, J.S., Kim, D.K., Kim, Y.H., and Kim, C.S. (2018). Adenosine induces intrinsic apoptosis via the PI3K/Akt/mTOR signaling pathway in human pharyngeal squamous carcinoma FaDu cells. Oncol Lett 15, 64896496. 10.3892/ol.2018.8089.

Compton, C.H., Gubb, J., Nieman, R., Edelson, J., Amit, O., Bakst, A., Ayres, J.G., Creemers, J.P., Schultze-Werninghaus, G., Brambilla, C., and Barnes, N.C. (2001). Cilomilast, a selective phosphodiesterase-4 inhibitor for treatment of patients with chronic obstructive pulmonary disease: a randomised, dose-ranging study. Lancet 358, 265-270. 10.1016/s0140-6736(01)05481-2.

Corradetti, M.N., Inoki, K., Bardeesy, N., DePinho, R.A., and Guan, K.L. (2004). Regulation of the TSC pathway by LKB1: evidence of a molecular link between tuberous sclerosis complex and Peutz-Jeghers syndrome. Genes Dev 18, 1533-1538. 10.1101/gad.1199104. 
de Wit, R.H., Mujić-Delić, A., van Senten, J.R., Fraile-Ramos, A., Siderius, M., and Smit, M.J. (2016). Human cytomegalovirus encoded chemokine receptor US28 activates the HIF-1a/PKM2 axis in glioblastoma cells. Oncotarget 7, 67966-67985. 10.18632/oncotarget.11817.

Defer, N., Best-Belpomme, M., and Hanoune, J. (2000). Tissue specificity and physiological relevance of various isoforms of adenylyl cyclase. Am J Physiol Renal Physiol 279, F400-416. 10.1152/ajprenal.2000.279.3.F400.

Demetriades, C., Doumpas, N., and Teleman, A.A. (2014). Regulation of TORC1 in response to amino acid starvation via lysosomal recruitment of TSC2. Cell 156, 786799. 10.1016/j.cell.2014.01.024.

DeYoung, M.P., Horak, P., Sofer, A., Sgroi, D., and Ellisen, L.W. (2008). Hypoxia regulates TSC1/2-mTOR signaling and tumor suppression through REDD1-mediated 14-3-3 shuttling. Genes \& development 22, 239-251. 10.1101/gad.1617608.

Di Mise, A., Tamma, G., Ranieri, M., Centrone, M., van den Heuvel, L., Mekahli, D., Levtchenko, E.N., and Valenti, G. (2018). Activation of Calcium-Sensing Receptor increases intracellular calcium and decreases cAMP and mTOR in PKD1 deficient cells. Scientific Reports 8, 5704. 10.1038/s41598-018-23732-5.

Díaz-Alonso, J., Aguado, T., de Salas-Quiroga, A., Ortega, Z., Guzmán, M., and GalveRoperh, I. (2015). CB1 Cannabinoid Receptor-Dependent Activation of mTORC1/Pax6 Signaling Drives Tbr2 Expression and Basal Progenitor Expansion in the Developing Mouse Cortex. Cerebral Cortex 25, 2395-2408. 10.1093/cercor/bhu039.

Dolma, S., Selvadurai, H.J., Lan, X., Lee, L., Kushida, M., Voisin, V., Whetstone, H., So, M., Aviv, T., Park, N., et al. (2016). Inhibition of Dopamine Receptor D4 Impedes Autophagic Flux, Proliferation, and Survival of Glioblastoma Stem Cells. Cancer Cell 29, 859-873. https://doi.org/10.1016/j.ccell.2016.05.002.

Dong, L., Zhang, B., Wu, L., Shang, Z., Liu, S., Jiang, X., Wang, H., Fan, L., Zhang, Y., and Xiao, H. (2020). Proteomics Analysis of Cellular BRS3 Receptor Activation Reveals Potential Mechanism for Signal Transduction and Cell Proliferation. Journal of Proteome Research 19, 1513-1521. 10.1021/acs.jproteome.9b00760.

Doskeland, S.O., Maronde, E., and Gjertsen, B.T. (1993). The genetic subtypes of cAMP-dependent protein kinase--functionally different or redundant? Biochim Biophys Acta 1178, 249-258. 10.1016/0167-4889(93)90201-y.

Eichel, K., and von Zastrow, M. (2018). Subcellular Organization of GPCR Signaling. Trends Pharmacol Sci 39, 200-208. 10.1016/j.tips.2017.11.009. 
Esseltine, J.L., and Scott, J.D. (2013). AKAP signaling complexes: pointing towards the next generation of therapeutic targets? Trends Pharmacol Sci 34, 648-655. 10.1016/j.tips.2013.10.005.

Fasano, C., Poirier, A., DesGroseillers, L., and Trudeau, L.E. (2008). Chronic activation of the D2 dopamine autoreceptor inhibits synaptogenesis in mesencephalic dopaminergic neurons in vitro. Eur $\mathrm{J}$ Neurosci 28, 1480-1490. 10.1111/j.14609568.2008.06450.x.

Feng, Z., Hu, W., de Stanchina, E., Teresky, A.K., Jin, S., Lowe, S., and Levine, A.J. (2007). The regulation of AMPK beta1, TSC2, and PTEN expression by p53: stress, cell and tissue specificity, and the role of these gene products in modulating the IGF-1-AKTmTOR pathways. Cancer Res 67, 3043-3053. 10.1158/0008-5472.CAN-06-4149.

Fraenkel, M., Ketzinel-Gilad, M., Ariav, Y., Pappo, O., Karaca, M., Castel, J., Berthault, M.F., Magnan, C., Cerasi, E., Kaiser, N., and Leibowitz, G. (2008). mTOR inhibition by rapamycin prevents beta-cell adaptation to hyperglycemia and exacerbates the metabolic state in type 2 diabetes. Diabetes 57, 945-957. 10.2337/db07-0922.

Gan, L., Seki, A., Shen, K., Iyer, H., Han, K., Hayer, A., Wollman, R., Ge, X., Lin, J.R., Dey, G., et al. (2019). The lysosomal GPCR-like protein GPR137B regulates Rag and mTORC1 localization and activity. Nat Cell Biol 21, 614-626. 10.1038/s41556-0190321-6.

Ghosh, P.M., Mikhailova, M., Bedolla, R., and Kreisberg, J.I. (2001). Arginine vasopressin stimulates mesangial cell proliferation by activating the epidermal growth factor receptor. Am J Physiol Renal Physiol 280, F972-979. 10.1152/ajprenal.2001.280.6.F972.

Gillespie, P.G., and Beavo, J.A. (1989). Inhibition and stimulation of photoreceptor phosphodiesterases by dipyridamole and M\&B 22,948. Mol Pharmacol 36, 773-781.

Hanlon, C.D., and Andrew, D.J. (2015). Outside-in signaling--a brief review of GPCR signaling with a focus on the Drosophila GPCR family. J Cell Sci 128, 3533-3542. $10.1242 / j c s .175158$.

Hara, K., Maruki, Y., Long, X., Yoshino, K., Oshiro, N., Hidayat, S., Tokunaga, C., Avruch, J., and Yonezawa, K. (2002). Raptor, a binding partner of target of rapamycin (TOR), mediates TOR action. Cell 110, 177-189. 10.1016/s0092-8674(02)00833-4.

Hara, K., Yonezawa, K., Weng, Q.P., Kozlowski, M.T., Belham, C., and Avruch, J. (1998). Amino acid sufficiency and mTOR regulate p70 S6 kinase and elF-4E BP1 through a common effector mechanism. J Biol Chem 273, 14484-14494. 10.1074/jbc.273.23.14484.

Hay, N., and Sonenberg, N. (2004). Upstream and downstream of mTOR. Genes Dev 18, 1926-1945. 10.1101/gad.1212704. 
Heitman, J., Movva, N.R., and Hall, M.N. (1991). Targets for cell cycle arrest by the immunosuppressant rapamycin in yeast. Science 253, 905-909. 10.1126/science.1715094.

Hilger, D., Masureel, M., and Kobilka, B.K. (2018). Structure and dynamics of GPCR signaling complexes. Nat Struct Mol Biol 25, 4-12. 10.1038/s41594-017-0011-7.

Ilouz, R., Bubis, J., Wu, J., Yim, Y.Y., Deal, M.S., Kornev, A.P., Ma, Y., Blumenthal, D.K., and Taylor, S.S. (2012). Localization and quaternary structure of the PKA Rlbeta holoenzyme. Proc Natl Acad Sci U S A 109, 12443-12448. 10.1073/pnas.1209538109.

Inoki, K., Li, Y., Xu, T., and Guan, K.L. (2003a). Rheb GTPase is a direct target of TSC2 GAP activity and regulates mTOR signaling. Genes Dev 17, 1829-1834. 10.1101/gad.1110003.

Inoki, K., Zhu, T., and Guan, K.L. (2003b). TSC2 mediates cellular energy response to control cell growth and survival. Cell 115, 577-590. 10.1016/s0092-8674(03)00929-2.

Insel, P.A., Snead, A., Murray, F., Zhang, L., Yokouchi, H., Katakia, T., Kwon, O., Dimucci, D., and Wilderman, A. (2012). GPCR expression in tissues and cells: are the optimal receptors being used as drug targets? Br J Pharmacol 165, 1613-1616.

10.1111/j.1476-5381.2011.01434.x.

Jewell, J.L., Fu, V., Hong, A.W., Yu, F.X., Meng, D., Melick, C.H., Wang, H., Lam, W.M., Yuan, H.X., Taylor, S.S., and Guan, K.L. (2019). GPCR signaling inhibits mTORC1 via PKA phosphorylation of Raptor. Elife 8. 10.7554/eLife.43038.

Jewell, J.L., Kim, Y.C., Russell, R.C., Yu, F.-X., Park, H.W., Plouffe, S.W., Tagliabracci, V.S., and Guan, K.-L. (2015). Metabolism. Differential regulation of mTORC1 by leucine and glutamine. Science (New York, N.Y.) 347, 194-198. 10.1126/science.1259472.

Jiang, S.-H., Li, J., Dong, F.-Y., Yang, J.-Y., Liu, D.-J., Yang, X.-M., Wang, Y.-H., Yang, M.-W., Fu, X.-L., Zhang, X.-X., et al. (2017). Increased Serotonin Signaling Contributes to the Warburg Effect in Pancreatic Tumor Cells Under Metabolic Stress and Promotes Growth of Pancreatic Tumors in Mice. Gastroenterology 153, 277-291.e219.

https://doi.org/10.1053/j.gastro.2017.03.008.

Jung, M.J., Rho, J.K., Kim, Y.M., Jung, J.E., Jin, Y.B., Ko, Y.G., Lee, J.S., Lee, S.J., Lee, J.C., and Park, M.J. (2013). Upregulation of CXCR4 is functionally crucial for maintenance of stemness in drug-resistant non-small cell lung cancer cells. Oncogene 32, 209-221. 10.1038/onc.2012.37.

Kadamur, G., and Ross, E.M. (2013). Mammalian phospholipase C. Annu Rev Physiol 75, 127-154. 10.1146/annurev-physiol-030212-183750. 
Kapiloff, M.S., Rigatti, M., and Dodge-Kafka, K.L. (2014). Architectural and functional roles of A kinase-anchoring proteins in cAMP microdomains. J Gen Physiol 143, 9-15. 10.1085/jgp.201311020.

Katoh, H., Aoki, J., Yamaguchi, Y., Kitano, Y., Ichikawa, A., and Negishi, M. (1998). Constitutively active Galpha12, Galpha13, and Galphaq induce Rho-dependent neurite retraction through different signaling pathways. J Biol Chem 273, 28700-28707. 10.1074/jbc.273.44.28700.

Kim, D.H., Sarbassov, D.D., Ali, S.M., King, J.E., Latek, R.R., Erdjument-Bromage, H., Tempst, P., and Sabatini, D.M. (2002). mTOR interacts with raptor to form a nutrientsensitive complex that signals to the cell growth machinery. Cell 110, 163-175. 10.1016/s0092-8674(02)00808-5.

Kim, D.H., Sarbassov, D.D., Ali, S.M., Latek, R.R., Guntur, K.V., Erdjument-Bromage, H., Tempst, P., and Sabatini, D.M. (2003). GbetaL, a positive regulator of the rapamycin-sensitive pathway required for the nutrient-sensitive interaction between raptor and mTOR. Mol Cell 11, 895-904. 10.1016/s1097-2765(03)00114-X.

Kim, E., Goraksha-Hicks, P., Li, L., Neufeld, T.P., and Guan, K.L. (2008). Regulation of TORC1 by Rag GTPases in nutrient response. Nat Cell Biol 10, 935-945. 10.1038/ncb1753.

Kim, H.K., Hwang, S.-H., Oh, E., and Abdi, S. (2017). Rolipram, a Selective Phosphodiesterase 4 Inhibitor, Ameliorates Mechanical Hyperalgesia in a Rat Model of Chemotherapy-Induced Neuropathic Pain through Inhibition of Inflammatory Cytokines in the Dorsal Root Ganglion. Frontiers in Pharmacology 8. 10.3389/fphar.2017.00885.

Kim, J., and Guan, K.-L. (2019). mTOR as a central hub of nutrient signalling and cell growth. Nature Cell Biology 21, 63-71. 10.1038/s41556-018-0205-1.

Kritzer, M.D., Li, J., Dodge-Kafka, K., and Kapiloff, M.S. (2012). AKAPs: the architectural underpinnings of local cAMP signaling. J Mol Cell Cardiol 52, 351-358. 10.1016/j.yjmcc.2011.05.002.

Lamming, D.W., Ye, L., Katajisto, P., Goncalves, M.D., Saitoh, M., Stevens, D.M., Davis, J.G., Salmon, A.B., Richardson, A., Ahima, R.S., et al. (2012). RapamycinInduced Insulin Resistance Is Mediated by mTORC2 Loss and Uncoupled from Longevity. Science 335, 1638-1643. doi:10.1126/science.1215135.

Le, K., Steagall, W.K., Stylianou, M., Pacheco-Rodriguez, G., Darling, T.N., Vaughan, M., and Moss, J. (2018). Effect of beta-agonists on LAM progression and treatment. Proc Natl Acad Sci U S A 115, E944-E953. 10.1073/pnas.1719960115. 
Lee, D.F., Kuo, H.P., Chen, C.T., Hsu, J.M., Chou, C.K., Wei, Y., Sun, H.L., Li, L.Y., Ping, B., Huang, W.C., et al. (2007). IKK beta suppression of TSC1 links inflammation and tumor angiogenesis via the mTOR pathway. Cell 130, 440-455.

10.1016/j.cell.2007.05.058.

Li, J., Ning, Y., Hedley, W., Saunders, B., Chen, Y., Tindill, N., Hannay, T., and Subramaniam, S. (2002). The Molecule Pages database. Nature 420, 716-717. 10.1038/nature01307.

Li, S.-H., Lu, H.-I., Chang, A.Y.W., Huang, W.-T., Lin, W.-C., Lee, C.-C., Tien, W.-Y., Lan, Y.-C., Tsai, H.-T., and Chen, C.-H. (2016a). Angiotensin II type I receptor (AT1R) is an independent prognosticator of esophageal squamous cell carcinoma and promotes cells proliferation via mTOR activation. Oncotarget 7, 67150-67165. 10.18632/oncotarget.11567.

Li, Y., Inoki, K., Vacratsis, P., and Guan, K.L. (2003). The p38 and MK2 kinase cascade phosphorylates tuberin, the tuberous sclerosis 2 gene product, and enhances its interaction with 14-3-3. J Biol Chem 278, 13663-13671. 10.1074/jbc.M300862200 M300862200 [pii].

Li, Z., Ji, X., Wang, W., Liu, J., Liang, X., Wu, H., Liu, J., Eggert, U.S., Liu, Q., and Zhang, X. (2016b). Ammonia Induces Autophagy through Dopamine Receptor D3 and MTOR. PLOS ONE 11, e0153526. 10.1371/journal.pone.0153526.

Liu, D., Bordicchia, M., Zhang, C., Fang, H., Wei, W., Li, J.L., Guilherme, A., Guntur, K., Czech, M.P., and Collins, S. (2016). Activation of mTORC1 is essential for betaadrenergic stimulation of adipose browning. J Clin Invest 126, 1704-1716. 10.1172/JCI83532.

Liu, D., Ceddia, R.P., and Collins, S. (2018). Cardiac natriuretic peptides promote adipose 'browning' through mTOR complex-1. Mol Metab 9, 192-198. 10.1016/j.molmet.2017.12.017.

Liu, G.Y., and Sabatini, D.M. (2020). mTOR at the nexus of nutrition, growth, ageing and disease. Nat Rev Mol Cell Biol 21, 183-203. 10.1038/s41580-019-0199-y.

Liu, J.J., Chiu, Y.T., DiMattio, K.M., Chen, C., Huang, P., Gentile, T.A., Muschamp, J.W., Cowan, A., Mann, M., and Liu-Chen, L.Y. (2019). Phosphoproteomic approach for agonist-specific signaling in mouse brains: mTOR pathway is involved in kappa opioid aversion. Neuropsychopharmacology 44, 939-949. 10.1038/s41386-018-0155-0.

Long, X., Lin, Y., Ortiz-Vega, S., Yonezawa, K., and Avruch, J. (2005). Rheb binds and regulates the mTOR kinase. Curr Biol 15, 702-713. 10.1016/j.cub.2005.02.053. Ma, L., Chen, Z., Erdjument-Bromage, H., Tempst, P., and Pandolfi, P.P. (2005). Phosphorylation and functional inactivation of TSC2 by Erk implications for tuberous sclerosis and cancer pathogenesis. Cell 121, 179-193. 10.1016/j.cell.2005.02.031. 
Ma, T., Hoeffer, C.A., Capetillo-Zarate, E., Yu, F., Wong, H., Lin, M.T., Tampellini, D., Klann, E., Blitzer, R.D., and Gouras, G.K. (2010). Dysregulation of the mTOR pathway mediates impairment of synaptic plasticity in a mouse model of Alzheimer's disease. PLoS One 5. 10.1371/journal.pone.0012845.

Martin, P.Y., Doly, S., Hamieh, A.M., Chapuy, E., Canale, V., Drop, M., ChaumontDubel, S., Bantreil, X., Lamaty, F., Bojarski, A.J., et al. (2020). mTOR activation by constitutively active serotonin6 receptors as new paradigm in neuropathic pain and its treatment. Prog Neurobiol 193, 101846. 10.1016/j.pneurobio.2020.101846.

Mavrakis, M., Lippincott-Schwartz, J., Stratakis, C.A., and Bossis, I. (2006). Depletion of type IA regulatory subunit (Rlalpha) of protein kinase $A$ (PKA) in mammalian cells and tissues activates mTOR and causes autophagic deficiency. Hum Mol Genet 15, 29622971. 10.1093/hmg/ddl239.

Mavrakis, M., Lippincott-Schwartz, J., Stratakis, C.A., and Bossis, I. (2007). mTOR kinase and the regulatory subunit of protein kinase A (PRKAR1A) spatially and functionally interact during autophagosome maturation. Autophagy 3, 151-153. 10.4161/auto.3632.

Meffre, J., Chaumont-Dubel, S., Mannoury la Cour, C., Loiseau, F., Watson, D.J., Dekeyne, A., Seveno, M., Rivet, J.M., Gaven, F., Deleris, P., et al. (2012). 5-HT(6) receptor recruitment of mTOR as a mechanism for perturbed cognition in schizophrenia. EMBO Mol Med 4, 1043-1056. 10.1002/emmm.201201410.

Melick, C.H., and Jewell, J.L. (2020). Regulation of mTORC1 by Upstream Stimuli. Genes 11, 989.

Melick, C.H., Meng, D., and Jewell, J.L. (2020). A-kinase anchoring protein 8L interacts with mTORC1 and promotes cell growth. J Biol Chem 295, 8096-8105. 10.1074/jbc.AC120.012595.

Meng, D., Yang, Q., Melick, C.H., Park, B.C., Hsieh, T.S., Curukovic, A., Jeong, M.H., Zhang, J., James, N.G., and Jewell, J.L. (2021). ArfGAP1 inhibits mTORC1 lysosomal localization and activation. EMBO J, e106412. 10.15252/embj.2020106412.

Meng, D., Yang, Q., Wang, H., Melick, C.H., Navlani, R., Frank, A.R., and Jewell, J.L. (2020). Glutamine and asparagine activate mTORC1 independently of Rag GTPases. J Biol Chem 295, 2890-2899. 10.1074/jbc.AC119.011578.

Menon, S., Dibble, C.C., Talbott, G., Hoxhaj, G., Valvezan, A.J., Takahashi, H., Cantley, L.C., and Manning, B.D. (2014). Spatial control of the TSC complex integrates insulin and nutrient regulation of mTORC1 at the lysosome. Cell 156, 771-785. 10.1016/j.cell.2013.11.049. 
Mohan, M.L., Vasudevan, N.T., Gupta, M.K., Martelli, E.E., and Naga Prasad, S.V. (2012). G-protein coupled receptor resensitization-appreciating the balancing act of receptor function. Curr Mol Pharmacol.

Monfar, M., Lemon, K.P., Grammer, T.C., Cheatham, L., Chung, J., Vlahos, C.J., and Blenis, J. (1995). Activation of pp70/85 S6 kinases in interleukin-2-responsive lymphoid cells is mediated by phosphatidylinositol 3-kinase and inhibited by cyclic AMP.

Molecular and cellular biology 15, 326-337. 10.1128/MCB.15.1.326.

Moore, S.F., Hunter, R.W., and Hers, I. (2014). Protein kinase C and P2Y12 take center stage in thrombin-mediated activation of mammalian target of rapamycin complex 1 in human platelets. J Thromb Haemost 12, 748-760. 10.1111/jth.12552.

Mothe-Satney, I., Gautier, N., Hinault, C., Lawrence, J.C., Jr., and Van Obberghen, E. (2004). In rat hepatocytes glucagon increases mammalian target of rapamycin phosphorylation on serine 2448 but antagonizes the phosphorylation of its downstream targets induced by insulin and amino acids. J Biol Chem 279, 42628-42637.

10.1074/jbc.M405173200.

Mullins, G.R., Wang, L., Raje, V., Sherwood, S.G., Grande, R.C., Boroda, S., Eaton, J.M., Blancquaert, S., Roger, P.P., Leitinger, N., and Harris, T.E. (2014). Catecholamine-induced lipolysis causes mTOR complex dissociation and inhibits glucose uptake in adipocytes. Proceedings of the National Academy of Sciences of the United States of America 111, 17450-17455. 10.1073/pnas.1410530111.

Nojima, H., Tokunaga, C., Eguchi, S., Oshiro, N., Hidayat, S., Yoshino, K., Hara, K., Tanaka, N., Avruch, J., and Yonezawa, K. (2003). The mammalian target of rapamycin (mTOR) partner, raptor, binds the mTOR substrates p70 S6 kinase and 4E-BP1 through their TOR signaling (TOS) motif. J Biol Chem 278, 15461-15464. 10.1074/jbc.C200665200.

Palazuelos, J., Ortega, Z., Díaz-Alonso, J., Guzmán, M., and Galve-Roperh, I. (2012). CB2 Cannabinoid Receptors Promote Neural Progenitor Cell Proliferation via mTORC1 Signaling*. Journal of Biological Chemistry 287, 1198-1209. https://doi.org/10.1074/jbc.M111.291294.

Paller, A.S., Tom, W.L., Lebwohl, M.G., Blumenthal, R.L., Boguniewicz, M., Call, R.S., Eichenfield, L.F., Forsha, D.W., Rees, W.C., Simpson, E.L., et al. (2016). Efficacy and safety of crisaborole ointment, a novel, nonsteroidal phosphodiesterase 4 (PDE4) inhibitor for the topical treatment of atopic dermatitis (AD) in children and adults. Journal of the American Academy of Dermatology 75, 494-503.e496. https://doi.org/10.1016/j.jaad.2016.05.046.

Pavlos, N.J., and Friedman, P.A. (2017). GPCR Signaling and Trafficking: The Long and Short of It. Trends Endocrinol Metab 28, 213-226. 10.1016/j.tem.2016.10.007. 
Pérez López, I., Cariolato, L., Maric, D., Gillet, L., Abriel, H., and Diviani, D. (2013). Akinase anchoring protein Lbc coordinates a p38 activating signaling complex controlling compensatory cardiac hypertrophy. Mol Cell Biol 33, 2903-2917. 10.1128/mcb.0003113.

Popova, N.V., and Jücker, M. (2021). The Role of mTOR Signaling as a Therapeutic Target in Cancer. International journal of molecular sciences 22, 1743. 10.3390/ijms22041743.

Potter, C.J., Pedraza, L.G., and Xu, T. (2002). Akt regulates growth by directly phosphorylating Tsc2. Nat Cell Biol 4, 658-665. 10.1038/ncb840.

Rinaldi, L., Sepe, M., Delle Donne, R., Conte, K., Arcella, A., Borzacchiello, D., Amente, S., De Vita, F., Porpora, M., Garbi, C., et al. (2017). Mitochondrial AKAP1 supports mTOR pathway and tumor growth. Cell Death Dis 8, e2842. 10.1038/cddis.2017.241. Rocha, A.S., Paternot, S., Coulonval, K., Dumont, J.E., Soares, P., and Roger, P.P. (2008). Cyclic AMP inhibits the proliferation of thyroid carcinoma cell lines through regulation of CDK4 phosphorylation. Mol Biol Cell 19, 4814-4825. 10.1091/mbc.E08-060617.

Rogala, K.B., Gu, X., Kedir, J.F., Abu-Remaileh, M., Bianchi, L.F., Bottino, A.M.S., Dueholm, R., Niehaus, A., Overwijn, D., Fils, A.P., et al. (2019). Structural basis for the docking of mTORC1 on the lysosomal surface. Science 366, 468-475. 10.1126/science.aay0166.

Roux, P.P., Ballif, B.A., Anjum, R., Gygi, S.P., and Blenis, J. (2004). Tumor-promoting phorbol esters and activated Ras inactivate the tuberous sclerosis tumor suppressor complex via p90 ribosomal S6 kinase. Proc Natl Acad Sci U S A 101, 13489-13494. 10.1073/pnas.0405659101.

Sabatini, D.M., Erdjument-Bromage, H., Lui, M., Tempst, P., and Snyder, S.H. (1994). RAFT1: a mammalian protein that binds to FKBP12 in a rapamycin-dependent fashion and is homologous to yeast TORs. Cell 78, 35-43. 10.1016/0092-8674(94)90570-3.

Sabers, C.J., Martin, M.M., Brunn, G.J., Williams, J.M., Dumont, F.J., Wiederrecht, G., and Abraham, R.T. (1995). Isolation of a protein target of the FKBP12-rapamycin complex in mammalian cells. J Biol Chem 270, 815-822. 10.1074/jbc.270.2.815.

Sancak, Y., Bar-Peled, L., Zoncu, R., Markhard, A.L., Nada, S., and Sabatini, D.M. (2010). Ragulator-Rag complex targets mTORC1 to the lysosomal surface and is necessary for its activation by amino acids. Cell 141, 290-303. 10.1016/j.cell.2010.02.024.

Sancak, Y., Peterson, T.R., Shaul, Y.D., Lindquist, R.A., Thoreen, C.C., Bar-Peled, L., and Sabatini, D.M. (2008). The Rag GTPases bind raptor and mediate amino acid signaling to mTORC1. Science 320, 1496-1501. 10.1126/science.1157535. 
Sassone-Corsi, P. (2012). The cyclic AMP pathway. Cold Spring Harb Perspect Biol 4. 10.1101/cshperspect.a011148.

Saxton, R.A., and Sabatini, D.M. (2017). mTOR Signaling in Growth, Metabolism, and Disease. Cell 169, 361-371. 10.1016/j.cell.2017.03.035.

Schalm, S.S., Fingar, D.C., Sabatini, D.M., and Blenis, J. (2003). TOS motif-mediated raptor binding regulates 4E-BP1 multisite phosphorylation and function. Curr Biol 13, 797-806. 10.1016/s0960-9822(03)00329-4.

Schett, G., Sloan, V.S., Stevens, R.M., and Schafer, P. (2010). Apremilast: a novel PDE4 inhibitor in the treatment of autoimmune and inflammatory diseases. Ther Adv Musculoskelet Dis 2, 271-278. 10.1177/1759720X10381432.

Scott, P.H., Belham, C.M., al-Hafidh, J., Chilvers, E.R., Peacock, A.J., Gould, G.W., and Plevin, R. (1996). A regulatory role for cAMP in phosphatidylinositol 3-kinase/p70 ribosomal S6 kinase-mediated DNA synthesis in platelet-derived-growth-factorstimulated bovine airway smooth-muscle cells. Biochem J 318 ( Pt 3), 965-971. $10.1042 / b j 3180965$.

Scott, P.H., and Lawrence, J.C., Jr. (1998). Attenuation of mammalian target of rapamycin activity by increased CAMP in 3T3-L1 adipocytes. J Biol Chem 273, 3449634501. 10.1074/jbc.273.51.34496.

Sekiguchi, T., Hirose, E., Nakashima, N., li, M., and Nishimoto, T. (2001). Novel G proteins, Rag C and Rag D, interact with GTP-binding proteins, Rag A and Rag B. J Biol Chem 276, 7246-7257. 10.1074/jbc.M004389200.

Shumway, S.D., Li, Y., and Xiong, Y. (2003). 14-3-3beta binds to and negatively regulates the tuberous sclerosis complex 2 (TSC2) tumor suppressor gene product, tuberin. J Biol Chem 278, 2089-2092. 10.1074/jbc.C200499200.

Smith, E.M., Finn, S.G., Tee, A.R., Browne, G.J., and Proud, C.G. (2005a). The tuberous sclerosis protein TSC2 is not required for the regulation of the mammalian target of rapamycin by amino acids and certain cellular stresses. J Biol Chem 280, 18717-18727. 10.1074/jbc.M414499200.

Smith, F.D., Langeberg, L.K., Cellurale, C., Pawson, T., Morrison, D.K., Davis, R.J., and Scott, J.D. (2010). AKAP-Lbc enhances cyclic AMP control of the ERK1/2 cascade. Nature cell biology 12, 1242-1249. 10.1038/ncb2130.

Smith, P.G., Wang, F., Wilkinson, K.N., Savage, K.J., Klein, U., Neuberg, D.S., Bollag, G., Shipp, M.A., and Aguiar, R.C.T. (2005b). The phosphodiesterase PDE4B limits cAMP-associated PI3K/AKT-dependent apoptosis in diffuse large B-cell lymphoma. Blood 105, 308-316. https://doi.org/10.1182/blood-2004-01-0240. 
Soliman, G.A., Acosta-Jaquez, H.A., and Fingar, D.C. (2010). mTORC1 inhibition via rapamycin promotes triacylglycerol lipolysis and release of free fatty acids in 3T3-L1 adipocytes. Lipids 45, 1089-1100. 10.1007/s11745-010-3488-y.

Solloway, M.J., Madjidi, A., Gu, C., Eastham-Anderson, J., Clarke, H.J., Kljavin, N., Zavala-Solorio, J., Kates, L., Friedman, B., Brauer, M., et al. (2015). Glucagon Couples Hepatic Amino Acid Catabolism to mTOR-Dependent Regulation of alpha-Cell Mass. Cell Rep 12, 495-510. 10.1016/j.celrep.2015.06.034.

Sriram, K., and Insel, P.A. (2018). G Protein-Coupled Receptors as Targets for Approved Drugs: How Many Targets and How Many Drugs? Mol Pharmacol 93, 251258. $10.1124 / \mathrm{mol} .117 .111062$.

Stan, R., McLaughlin, M.M., Cafferkey, R., Johnson, R.K., Rosenberg, M., and Livi, G.P. (1994). Interaction between FKBP12-rapamycin and TOR involves a conserved serine residue. J Biol Chem 269, 32027-32030.

Suh, J.M., Song, J.H., Kim, D.W., Kim, H., Chung, H.K., Hwang, J.H., Kim, J.M., Hwang, E.S., Chung, J., Han, J.H., et al. (2003). Regulation of the phosphatidylinositol 3-kinase, Akt/protein kinase B, FRAP/mammalian target of rapamycin, and ribosomal S6 kinase 1 signaling pathways by thyroid-stimulating hormone $(\mathrm{TSH})$ and stimulating type TSH receptor antibodies in the thyroid gland. J Biol Chem 278, 21960-21971. 10.1074/jbc.M300805200.

Sutton, L.P., and Caron, M.G. (2015). Essential role of D1R in the regulation of mTOR complex1 signaling induced by cocaine. Neuropharmacology 99, 610-619. 10.1016/j.neuropharm.2015.08.024.

Suzuki, N., Hajicek, N., and Kozasa, T. (2009). Regulation and physiological functions of G12/13-mediated signaling pathways. Neurosignals 17, 55-70. 10.1159/000186690.

Taylor, S.S., Wu, J., Bruystens, J.G.H., Del Rio, J.C., Lu, T.W., Kornev, A.P., and Ten Eyck, L.F. (2021). From structure to the dynamic regulation of a molecular switch: A journey over 3 decades. J Biol Chem 296, 100746. 10.1016/j.jbc.2021.100746.

Tee, A.R., Manning, B.D., Roux, P.P., Cantley, L.C., and Blenis, J. (2003). Tuberous sclerosis complex gene products, Tuberin and Hamartin, control mTOR signaling by acting as a GTPase-activating protein complex toward Rheb. Curr Biol 13, 1259-1268. 10.1016/s0960-9822(03)00506-2.

Teng, L.L., Lu, G.L., Chiou, L.C., Lin, W.S., Cheng, Y.Y., Hsueh, T.E., Huang, Y.C., Hwang, N.H., Yeh, J.W., Liao, R.M., et al. (2019). Serotonin receptor HTR6-mediated mTORC1 signaling regulates dietary restriction-induced memory enhancement. PLoS Biol 17, e2007097. 10.1371/journal.pbio.2007097.

Tian, T., Li, X., and Zhang, J. (2019). mTOR Signaling in Cancer and mTOR Inhibitors in Solid Tumor Targeting Therapy. International Journal of Molecular Sciences 20, 755. 
Vogler, O., Barcelo, J.M., Ribas, C., and Escriba, P.V. (2008). Membrane interactions of $\mathrm{G}$ proteins and other related proteins. Biochim Biophys Acta 1778, 1640-1652. 10.1016/j.bbamem.2008.03.008.

Wang, W., Guo, X., and Dan, H. (2020). alpha2A-Adrenergic Receptor Inhibits the Progression of Cervical Cancer Through Blocking PI3K/AKT/mTOR Pathway. Onco Targets Ther 13, 10535-10546. 10.2147/OTT.S264409.

Wang, Z., Liu, S., Kakizaki, M., Hirose, Y., Ishikawa, Y., Funato, H., Yanagisawa, M., Yu, Y., and Liu, Q. (2014). Orexin/hypocretin activates mTOR complex 1 (mTORC1) via an Erk/Akt-independent and calcium-stimulated lysosome v-ATPase pathway. J Biol Chem 289, 31950-31959. 10.1074/jbc.M114.600015.

Wauson, E.M., Zaganjor, E., Lee, A.Y., Guerra, M.L., Ghosh, A.B., Bookout, A.L., Chambers, C.P., Jivan, A., McGlynn, K., Hutchison, M.R., et al. (2012). The G proteincoupled taste receptor T1R1/T1R3 regulates mTORC1 and autophagy. Mol Cell 47, 851-862. 10.1016/j.molcel.2012.08.001.

Welles, J.E., Dennis, M.D., Jefferson, L.S., and Kimball, S.R. (2020). GlucagonDependent Suppression of mTORC1 is Associated with Upregulation of Hepatic FGF21 mRNA Translation. Am J Physiol Endocrinol Metab. 10.1152/ajpendo.00555.2019.

Wettschureck, N., and Offermanns, S. (2005). Mammalian G proteins and their cell type specific functions. Physiol Rev 85, 1159-1204. 10.1152/physrev.00003.2005.

Wittpoth, C., Scholich, K., Yigzaw, Y., Stringfield, T.M., and Patel, T.B. (1999). Regions on adenylyl cyclase that are necessary for inhibition of activity by beta gamma and $\mathrm{G}$ (ialpha) subunits of heterotrimeric $\mathrm{G}$ proteins. Proceedings of the National Academy of Sciences of the United States of America 96, 9551-9556. 10.1073/pnas.96.17.9551.

Wong, W., and Scott, J.D. (2004). AKAP signalling complexes: focal points in space and time. Nat Rev Mol Cell Biol 5, 959-970. 10.1038/nrm1527.

Wu, E.H., and Wong, Y.H. (2005). Involvement of G i/o proteins in nerve growth factorstimulated phosphorylation and degradation of tuberin in PC-12 cells and cortical neurons. Mol Pharmacol 67, 1195-1205. 10.1124/mol.104.007237.

Wu, E.H., and Wong, Y.H. (2006). Activation of muscarinic M4 receptor augments NGFinduced pro-survival Akt signaling in PC12 cells. Cell Signal 18, 285-293. 10.1016/j.cellsig.2005.04.009.

Xie, J., Ponuwei, G.A., Moore, C.E., Willars, G.B., Tee, A.R., and Herbert, T.P. (2011). cAMP inhibits mammalian target of rapamycin complex-1 and -2 (mTORC1 and 2) by promoting complex dissociation and inhibiting mTOR kinase activity. Cellular signalling 23, 1927-1935. 10.1016/j.cellsig.2011.06.025. 
Yang, H., Jiang, X., Li, B., Yang, H.J., Miller, M., Yang, A., Dhar, A., and Pavletich, N.P. (2017). Mechanisms of mTORC1 activation by RHEB and inhibition by PRAS40. Nature 552, 368-373. 10.1038/nature25023.

Ye, R., Pi, M., Nooh, M.M., Bahout, S.W., and Quarles, L.D. (2019). Human GPRC6A Mediates Testosterone-Induced Mitogen-Activated Protein Kinases and mTORC1 Signaling in Prostate Cancer Cells. Mol Pharmacol 95, 563-572. 10.1124/mol.118.115014.

Zaccolo, M., and Pozzan, T. (2003). CAMP and Ca2+ interplay: a matter of oscillation patterns. Trends Neurosci 26, 53-55. 10.1016/s0166-2236(02)00017-6.

Zaccolo, M., Zerio, A., and Lobo, M.J. (2021). Subcellular Organization of the CAMP Signaling Pathway. Pharmacological Reviews 73, 278. 10.1124/pharmrev.120.000086. Zhang, S., Wang, H., Melick, C.H., Jeong, M.-H., Curukovic, A., Tiwary, S., LamaSherpa, T.D., Meng, D., Servage, K.A., James, N.G., and Jewell, J.L. (2021). AKAP13 couples GPCR signaling to mTORC1 inhibition. PLOS Genetics 17, e1009832. 10.1371/journal.pgen.1009832.

Zhang, X., Feng, Q., and Cote, R.H. (2005). Efficacy and selectivity of phosphodiesterase-targeted drugs in inhibiting photoreceptor phosphodiesterase (PDE6) in retinal photoreceptors. Invest Ophthalmol Vis Sci 46, 3060-3066. 10.1167/iovs.05-0257.

Zheng, X.F., Florentino, D., Chen, J., Crabtree, G.R., and Schreiber, S.L. (1995). TOR kinase domains are required for two distinct functions, only one of which is inhibited by rapamycin. Cell 82, 121-130. 10.1016/0092-8674(95)90058-6. 


\section{Funding:}

This work was supported by The Welch Foundation [1-1927-20200401]; American Cancer Society Institutional Research Grants [133894-RSG-19-162-01-TBE]; the American Cancer Society Institutional Research Grants [ACS-IRG-17-174-13] and National Institutes of Health (R01GM129097-01) to J.L.J.

\section{Conflict of interest:}

The authors declare they have no conflicts of interest with the contents of this article. 


\section{Figure Legends}

Figure 1. mTORC1 regulation by upstream stimuli. All positive regulators (green) and negative regulators (red) mTORC1 converge on tuberous sclerosis complex (TSC) regulation. Growth factors control the binding of insulin receptor substrate (IRS) proteins which activate phosphoinositide 3-kinase (PI3K) and lead to phosphorylation of phosphatidylinositol 4,5-bisphosphate $\left(\mathrm{PIP}_{2}\right)$ to phosphatidylinositol 3,4,5-triphosphate $\left(\mathrm{PIP}_{3}\right)$. PTEN negatively regulates this activation. $\mathrm{PIP}_{3}$ subsequently activates phosphoinositide-dependent kinase 1/2 (PDK1/2) which in turn activates plasma membrane-localized AKT. mTORC2 can also phosphorylate AKT. AKT activates mTORC1 through phosphorylation of TSC, which activates Ras homolog enriched in brain (Rheb). TSC is inhibited through extracellular signal-related kinase (Erk) by the Ras-Raf-Mek-Erk signaling cascade. Tumor necrosis factor $\alpha(\mathrm{TNF} \alpha)$ and hypoxia secondarily regulate mTORC1 through IKB kinase $\beta$ (IKK $\beta$ ), and DNA damage response 1 (REDD1) respectively. Wingless- 
type (Wnt) signaling inhibits TSC by inhibiting glycogen synthase kinase 3 (GSK3). Cellular stress and DNA damage trigger AMP-activated protein kinase (AMPK) activation through p53 and liver kinase B1 (LKB1) respectively to inhibit mTORC1.

Figure 2. mTORC1 senses two different amino acid signaling cascades. (A) The Rag-dependent signaling pathway is stimulated by amino acids such as Ala, His, Ser, Met, Thr, Val, Leu, and Arg and converges on the Rag GTPases. Following activation, RagA or RagB is GTP-bound and heterodimerizes with RagC or RagD. Rag GTPase heterodimer directly interacts with the Raptor subunit of the mTORC1 at the lysosome. Finally, Ras homolog enriched in brain (Rheb) activates the mTORC1. (B) The Rag-independent signaling pathway is stimulated by the addition of amino acids such as Gln and Asn. The small GTPase Adenosine diphosphate ribosylation factor 1 (Arf1), vacuolar H+-ATPase (v-ATPase), and Rheb are necessary components of the Rag GTPase independent pathway. The cycling of Arf1 to a GTP-bound state through guanine nucleotide exchange factor (GEF) and GDP-bound state through GTPase activating protein (GAP) promotes mTORC1 activation and lysosomal localization. v-ATPase is present at the lysosome and required for amino acid signaling to $\mathrm{mTORC} 1$ for both pathways.

Figure 3. $\mathrm{G} \alpha_{s}$-coupled G-protein coupled receptor (GPCR) inhibition of mTORC1. Ligand binding activates GPCRs resulting in the $\mathrm{G} \alpha$ protein switching from inactive GDP-bound state to active GTP-bound state, leading to a $\mathrm{G} \alpha$ subunit dissociation following conformational change from the GßY complex. The GTP-bound G $\alpha_{s}$ subunit can activate Adenylyl Cyclase (AC), which converts ATP to cAMP. 
Elevated cAMP activates protein kinase $A(P K A)$ by binding to its regulatory subunit and releasing PKA's catalytic subunits. AKAPs act as a scaffolding protein that assists in PKA localization to distinct compartments in the cell to facilitate signaling cascades. PKA mediated phosphorylation of Raptor at Ser 971 to inhibit mTORC1. Phosphodiesterase (PDE) negatively regulates the CAMP signaling by hydrolyzing CAMP to AMP.

Table 1.

\begin{tabular}{|c|c|c|c|c|}
\hline GPCR & G-protein & Model/Cell Line & $\begin{array}{l}\text { mTORC1 } \\
\text { Activity }\end{array}$ & Reference \\
\hline$\alpha 2-A R$ & $\mathrm{G} \alpha(\mathrm{i} / \mathrm{o})$ & $\begin{array}{c}\text { PC-12; } \\
\text { FaDu; } \\
\text { Cervical cancer cell lines ( } \\
\text { HeLa, Caski, C-33A and } \\
\text { SiHa) }\end{array}$ & $\begin{array}{l}\text { Increase; } \\
\text { Decrease; } \\
\text { Decrease }\end{array}$ & $\begin{array}{l}\text { (Wu and Wong, 2005) } \\
\text { (Choi et al., 2018) } \\
\text { (Wang et al., 2020) }\end{array}$ \\
\hline AVP & $\mathrm{G} \alpha(\mathrm{s})$ & primary hepatocytes & Decrease & (Jewell et al., 2019) \\
\hline$\beta 1 / \beta 2-A R$ & $\mathrm{G} \alpha(\mathrm{s})$ & $\begin{array}{l}\text { Various cell lines, mouse } \\
\text { brain \& liver; } \\
\text { 3T3-L1 adipocytes, mouse }\end{array}$ & Decrease & (Jewell et al., 2019) \\
\hline & & $\begin{array}{l}\text { brown adipose tissue; } \\
\text { Human } \mathrm{TSC}^{+/} \text {fibroblasts }\end{array}$ & $\begin{array}{l}\text { Increase } \\
\text { Increase }\end{array}$ & $\begin{array}{l}\text { (Liu et al., 2016) } \\
\text { (Le et al., 2018) }\end{array}$ \\
\hline CXCR4 & $\mathrm{G} \alpha(\mathrm{i} / \mathrm{o})$ & Gefitinib resistant A549 & Increase & (Jung et al., 2013) \\
\hline GCGR & $\mathrm{G} \alpha(\mathrm{s})$ & $\begin{array}{c}\text { Primary hepatocytes; } \\
\text { Mouse pancreatic } \alpha \text {-cells; } \\
\text { Rat hepatocytes,H4IIE, } \\
\text { HepG2 }\end{array}$ & Decrease & $\begin{array}{c}\text { (Jewell et al., 2019) } \\
\text { (Solloway et al., 2015) } \\
\text { (Welles et al., 2020) }\end{array}$ \\
\hline GLP-1 & $\mathrm{G} \alpha(\mathrm{s})$ & BRIN-BD11 & Increase & (Carlessi et al., 2017) \\
\hline GPR137B & unknown & $\begin{array}{l}\text { MEF, HEK-293T/E, HAP1, } \\
\text { HeLa, Hs68, zebrafish }\end{array}$ & Increase & (Gan et al., 2019) \\
\hline HTR6 & $\mathrm{G} \alpha(\mathrm{s})$ & $\begin{array}{l}\text { Mouse prefrontal cortex } \\
\text { Mouse hippocampal tissue; } \\
\text { Rat dorsal spinal cord }\end{array}$ & Increase & $\begin{array}{l}\text { (Meffre et al., 2012) } \\
\text { (Teng et al., 2019) } \\
\text { (Martin et al., 2020) }\end{array}$ \\
\hline KOR & $\mathrm{G} \alpha(\mathrm{i} / \mathrm{o})$ & $\begin{array}{l}\text { CD-1 male mice, N2A- } \\
\text { FmK6H cells }\end{array}$ & Increase & (Liu et al., 2019) \\
\hline $\mathrm{M}_{4} \mathrm{mAChR}$ & $\mathrm{G} \alpha(\mathrm{i} / \mathrm{o})$ & PC-12 & Increase & (Wu and Wong, 2006) \\
\hline mGluR & $\mathrm{G} \alpha(\mathrm{i} / \mathrm{o})$ & Primary neuronal & Increase & (Ma et al., 2010) \\
\hline OX1/2R & $\mathrm{G} \alpha(\mathrm{s})$ & HEK-293T, N41, MEF & Increase & (Wang et al., 2014) \\
\hline
\end{tabular}




\begin{tabular}{|c|c|c|c|c|}
\hline $\mathrm{PGE}_{2}$ & $\mathrm{G} \alpha(\mathrm{s})$ & PANC-1 & Increase & (Chang et al., 2015) \\
\hline PGF2 $\alpha$ & $\mathrm{G} \alpha(\mathrm{s})$ & bLCs & Increase & (Arvisais et al., 2006) \\
\hline $\mathrm{P}_{2} \mathrm{Y}_{12}$ & $\mathrm{G} \alpha(\mathrm{i} / \mathrm{o})$ & Human platelets & Increase & (Moore et al., 2014) \\
\hline T1R1/T1R3 & $\mathrm{G} \alpha(\mathrm{i} / \mathrm{o})$ & MIN6 & Increase & (Wauson et al., 2012) \\
\hline TSH & $\mathrm{G} \alpha(\mathrm{s})$ & Rat thyroid, $\mathrm{CHO}$ & Increase & (Suh et al., 2003) \\
\hline $\mathrm{V}_{1}$ & $\mathrm{G} \alpha(\mathrm{s})$ & Rat mesangial cells & Increase & (Ghosh et al., 2001) \\
\hline GPRC6A & Gai, Gaq & HEK293A, liver, PC-3 & Increase & (Ye et al., 2019) \\
\hline BRS-3 & $\mathrm{G} \alpha q$ & 3T3 fibroblast cell & Increase & (Dong et al., 2020) \\
\hline CaSR & $\mathrm{G} \alpha(\mathrm{i} / \mathrm{o})$ & cystic kidney epithelial cells & Increase & (Di Mise et al., 2018) \\
\hline US28 & $\mathrm{G} \alpha q$ & glioblastoma cells & Increase & (de Wit et al., 2016) \\
\hline 5-HT7 & $\mathrm{G} \alpha_{12}$ & endothelial cells & Increase & (Banskota et al., 2016) \\
\hline AT1R & $\mathrm{G} \alpha \mathrm{q}$ & ESCC & Increase & (Li et al., 2016a) \\
\hline HTR2B & $\mathrm{G} \alpha(\mathrm{i} / \mathrm{o})$ & PDAC cells & Increase & (Jiang et al., 2017) \\
\hline D1R & Gaq & nucleus accumbens of mice & Increase & (Sutton and Caron, 2015) \\
\hline OPRM1 & $\mathrm{G} \alpha(\mathrm{i} / \mathrm{o})$ & HEK293 cells & Increase & (Wang et al., 2014) \\
\hline DRD4 & $\mathrm{G} \alpha(\mathrm{i} / \mathrm{o})$ & GBM stem cells & Decrease & (Dolma et al., 2016) \\
\hline DRD3 & $\mathrm{G} \alpha(\mathrm{i} / \mathrm{o})$ & $\begin{array}{l}\text { HEK293T, HeLa, COS-7 } \\
\text { cells }\end{array}$ & Decrease & $\begin{array}{l}\text { (Barroso-Chinea et al., } \\
\text { 2020; Li et al., 2016b) }\end{array}$ \\
\hline $\mathrm{D} 2 \mathrm{R}$ & $\mathrm{G} \alpha(\mathrm{i} / \mathrm{o})$ & mesencephalic neurons & Decrease & (Fasano et al., 2008) \\
\hline CNR2 & $\mathrm{G} \alpha(\mathrm{i} / \mathrm{o})$ & Neural progenitor cell & Increase & (Palazuelos et al., 2012) \\
\hline CNR1 & $\mathrm{G} \alpha(\mathrm{i} / \mathrm{o})$ & Glial cells & Increase & (Díaz-Alonso et al., 2015) \\
\hline
\end{tabular}

Table 1. GPCRs that regulate mTORC1 activity. 5-Hydroxytryptamine (5-HT); Alpha-2 adrenergic receptor (B2-AR); Angiotensin II type I receptor (AT1R); Arg vasopressin receptor (AVP); Beta1/Beta-2 adrenergic receptor ( $\beta 1 / \beta 2-A R)$; calcium-sensing receptor (CaSR); C-X-C chemokine receptor 4 (CXCR4); dopamine D1 receptor (D1R); dopamine D2 receptor (D2R); Glucagon receptor (GCGR); Glucagon-like peptide 1 (GLP-1); GPCR 137B (GPR137B); 5-hydroxytryptamine receptor 6 (HTR6); kappa opioid receptor (KOR); Metabotropic glutamate receptor (mGluR); Muscarinic acetylcholine receptor $\mathrm{M} 4\left(\mathrm{M}_{4} \mathrm{mAChR}\right)$; Orexin 1/2 receptor $(\mathrm{OX} 1 / 2 \mathrm{R})$; Prostaglandin $\mathrm{E}_{2} / \mathrm{F} 2$-alpha receptor (PGE $/$ PGF2 $\alpha$ ); Purinergic Receptor (P2Y $\left.{ }_{12}\right)$; Taste receptor type 1 member 1/3 (T1R1/T1R3); Thyroid stimulating hormone receptor (TSH); Vasopressin V1 receptor $\left(\mathrm{V}_{1}\right)$; Opioid receptor mu 1; Rat adrenal gland cells (PC-12); Cell lines: Lung adenocarcinoma (A549); bovine steroidogenic luteal cells (bLCs); esophageal squamous cell carcinoma (ESCC); Chinese hamster ovary cells $(\mathrm{CHO})$; human pharyngeal squamous carcinoma (FaDu); haploid 1 cells (HAP1); Human embryonic kidney 293T cells (HEK-293T) Human pancreatic cancer (PANC-1); Henrietta Lacks cervical adenocarcinoma cells (HeLa); human primary fibroblasts (Hs68); Mouse embryonic fibroblast (MEF); mouse insulinoma 6 (MIN6); mouse neuro2A neuroblastoma with FmK6H construct 
(N2A-FmK6H); mouse embryonic hypothalamus N41 cells (N41); Rat pancreatic hybrid cells of NEDH and RINm5F (BRIN-BD11);

Table 2.

\begin{tabular}{cccc}
\hline PDE inhibitors & Target & Substrate & Reference \\
\hline Rolipram & PDE4 & cAMP & (Kim et al., 2017) \\
Apremilast & PDE4 & cAMP & (Schett et al., 2010) \\
Crisaborole & PDE4 & cAMP & (Paller et al., 2016) \\
Roflumilast & PDE4 & cAMP & (Baye, 2012) \\
Cilomilast & PDE4 & cAMP & (Compton et al., 2001) \\
Theophylline & $\begin{array}{c}\text { Non-selective } \\
\text { PDE4 } \\
\text { Dipyridamole }\end{array}$ & $\begin{array}{c}\text { Non-selective } \\
\text { PDE6, PDE8 } \\
\text { Zaprinast }\end{array}$ & cAMP \\
Non-selective & PDE6 & cAMP & (Barnes, 2013) \\
& cAMP & (Gillespie and Beavo, 1989) \\
& & (Zhang et al., 2005)
\end{tabular}


Molecular Pharmacology Fast Forward. Published on December 28, 2021 as DOI: 10.1124/molpharm.121.000302

This article has not been copyedited and formatted. The final version may differ from this version.

Table 2. Phosphodiesterase (PDE) with affinity to cAMP and their inhibitors. 
Figure 1

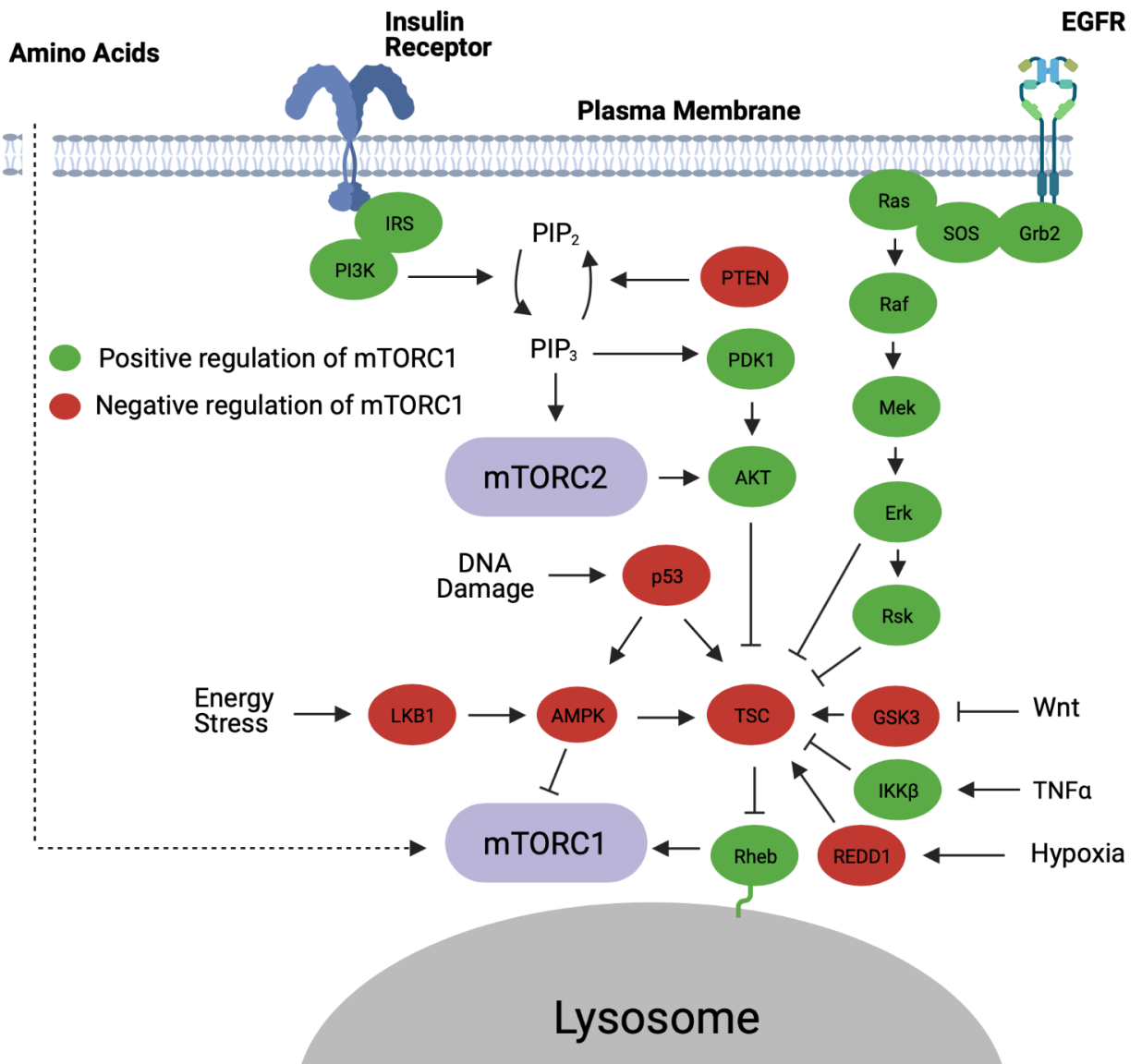

Amino Acids

Insulin

EGFR

Plasma Membrane

$\mathrm{PIP}_{3}$

PDK1

Mek

Energy

(GSK

mTORC1

\section{Lysosome}
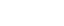
Figure 2

\section{Alanine \\ Histidine \\ Serine \\ Methionine \\ Threonine \\ Valine \\ Leucine \\ Arginine}

Multiple

Components

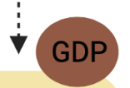

Rag C/D

Rag A/B mTORC1 GTP

v-ATPase

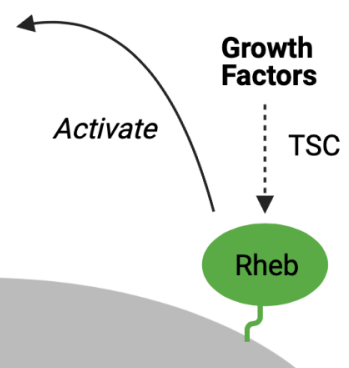

Lysosome

\section{Asparagine}

Glutamine
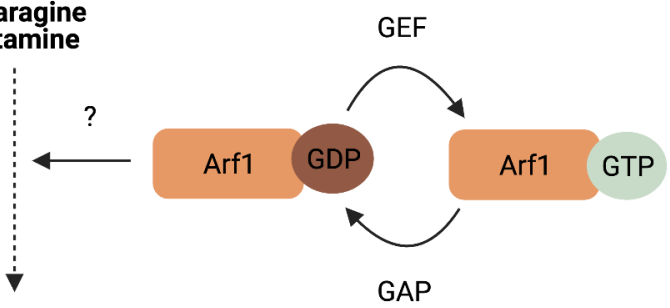

mTORC1

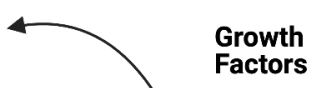

Activate

Factors

TSC 


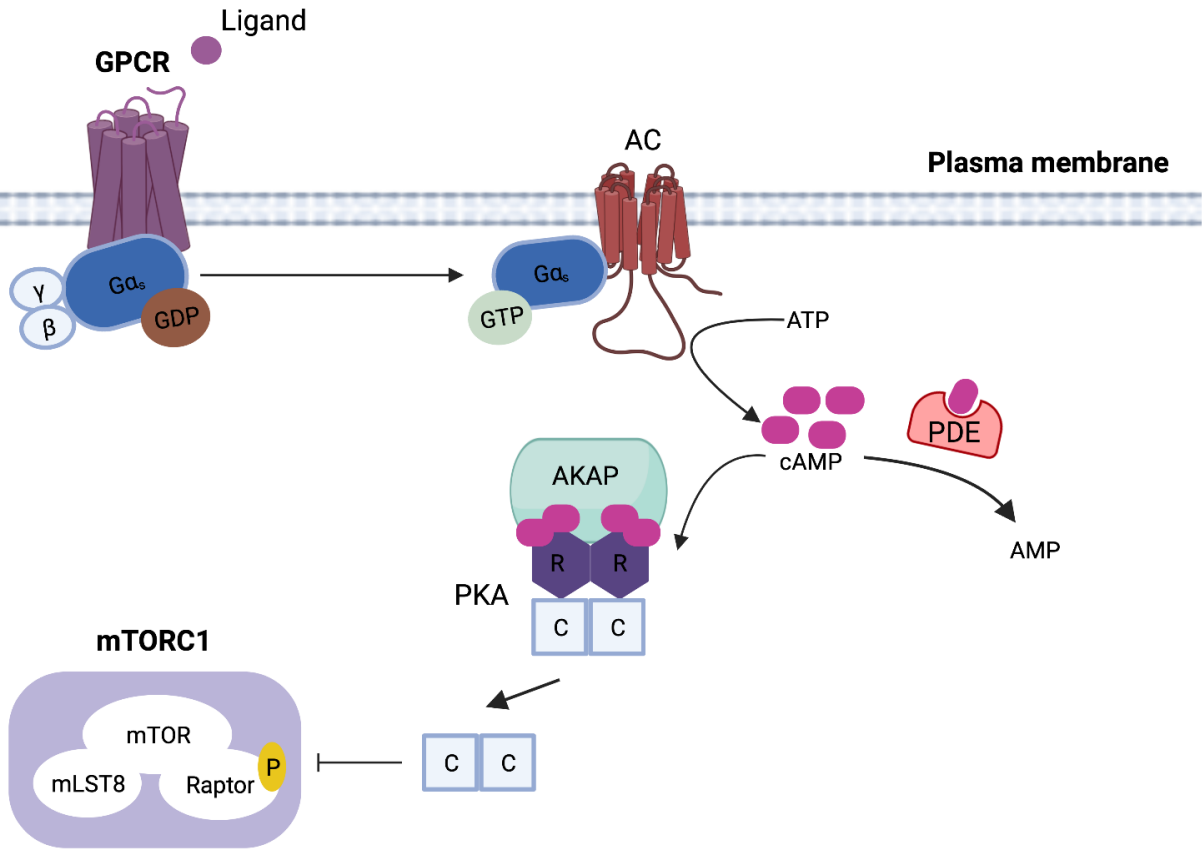

